\title{
Enfrentamentos e construçáo de projetos de trabalho para a superação da laborterapia
}

\author{
Fernando Sfair Kinker
}

Curso de Terapia Ocupacional, Universidade Federal de São Paulo - UNIFESP, Santos, SP, Brasil

\begin{abstract}
Resumo: O objetivo deste artigo é tecer uma reflexão sobre as contradições e o suposto potencial reabilitador da laborterapia a partir da experiência desenvolvida pelo Núcleo do Trabalho do Programa de Saúde Mental da cidade de Santos, SP, no período de 1989 a 1996, do início da intervenção no Hospital Anchieta, ao final do processo de implantação dos serviços comunitários e territoriais. A laborterapia é aqui caracterizada como uma tecnologia disciplinar de controle dos desvios, operando em sintonia com o paradigma psiquiátrico. Em sentido contrário, os projetos de trabalho que aliam saúde mental e economia solidária são considerados dispositivos de multiplicação de possibilidades, ampliação da rede de relações e transformação das condições concretas de vida, contribuindo para a desconstrução do paradigma psiquiátrico e da sociabilidade da mercadoria. As reflexões aqui apresentadas fazem parte de uma tese de doutorado que utilizou como método o relato da experiência de implantação do Núcleo, articulando-o à perspectiva teórica da desinstitucionalização e à discussão da complexidade, produzindo como resultados novas possibilidades emancipatórias no lidar com a questão do trabalho na área de saúde mental.
\end{abstract}

Palavras-chave: Terapia Ocupacional/Tendências, Trabalho, Desinstitucionalização, Saúde Mental.

\section{Confrontation and construction of work projects for overcoming labor- therapeutic practices}

\begin{abstract}
The objective of this paper is to make a reflection on the contradictions and the alleged rehabilitative potential of labor-therapeutic practices, starting from the experience developed by the Work Center of the Mental Health Program of the Municipality of Santos from 1989 to 1996, from the beginning of the intervention in the psychiatric hospital to the implementation of territorial and community services. The labor-therapeutic practice is characterized here as a disciplinary technology of deviation control, operating in line with the psychiatric paradigm. On the other hand, work projects that combine mental health and solidarity economy are considered devices that multiply opportunities, expand social networks and transform the concrete conditions of life, contributing to deconstruct the psychiatric paradigm and the sociability of merchandise. The ideas herein presented are part of a doctoral thesis that used the experience report of the Work Center implementation as a method, articulating the theoretical perspective of deinstitutionalization and the discussion of complexity, presenting new emancipatory possibilities of dealing with the issue of labor in the mental health field.
\end{abstract}

Keywords: Occupational Therapy/Trends, Labor, Deinstitutionalization, Mental Health. 


\section{Introdução}

O objetivo deste artigo é apresentar uma reflexão crítica sobre as contradiçôes e o suposto potencial reabilitador da laborterapia, tendo como referência a experiência desenvolvida pelo Núcleo do Trabalho do Programa de Saúde Mental de Santos, no período de 1989 a 1996, que vai praticamente do início da intervenção no Hospital Anchieta ao final do processo de implantaçáo dos cinco Núcleos de Atenção Psicossocial (Naps). Embora a experiência santista tenha sido relatada em muitas ocasiōes (CAPISTRANO FILHO; KINOSHITA, 1992; NICÁCIO, 1994, 2003; NICÁCIO; KINKER, 1996; KINOSHITA, 1996; REIS, 1998; ROBORTELLA, 2000; NOGUEIRA, 1997; KINKER, 1997, 2011; OGAWA, 1997; NASCIMENTO, 1997; CAPISTRANO, 1995), poucos estudos aprofundaram o sentido dos projetos de trabalho desenvolvidos pelos usuários do programa de saúde mental, confrontando-os com as tradicionais práticas da laborterapia. A importância de retomar uma experiência passada liga-se à possibilidade de ela dizer algo capaz de contribuir com os movimentos atuais e promissores que aliam saúde mental e economia solidária. Nesse sentido, o relato destina-se principalmente aos profissionais de saúde mental atualmente envolvidos nesses projetos, com o intuito de promover reflexóes, levantar possibilidades e estratégias para o desenvolvimento de projetos de trabalho no campo da saúde mental e no da reabilitação psicossocial ${ }^{1}$. Imersos em suas experiências, provavelmente esses atores se enxergarão nas páginas que se seguem e poderão se envolver e trazer para sua realidade a intensidade de transformaçóes que elas geraram.

No campo da reforma psiquiátrica brasileira, a experiência do Núcleo do Trabalho foi uma das primeiras a problematizar e a questionar frontalmente as relaçôes supostamente terapêuticas entre trabalho e psiquiatria, viabilizando, ao final de um período de sete anos de experimentação, a criação de uma Cooperativa de Trabalho formal e juridicamente constituída.

Associar as experiências vivenciadas - que modificaram as condições concretas de vida e a visão de mundo de profissionais e usuários - a uma crítica à laborterapia envolveu o diálogo permanente com um arcabouço teórico que será explicitado a seguir.

\section{Metodologia}

Construído a partir de uma tese de doutorado que procurou relatar e problematizar a experiência santista de construção de projetos de trabalho (KINKER, 2011), o presente trabalho pretende articular a experiência vivida, tendo como chave de leitura a perspectiva teórica da desinstitucionalizacão (ROTELLI, 1990, 1994; ROTELLI; DE LEONARDIS; MAURI, 1990) e a discussão da complexidade (MORIN, 1996, 2001, 2002).

A noçáo de desinstitucionalização como desconstruçáo de práticas, saberes, normas, leis e valores é sincrônica à ideia de complexidade. A mudança do objeto da psiquiatria, que de doença se transforma numa experiência existencial de sofrimento singular, mergulhada num mar revolto de relaçôes sociais (relaçôes que, através das respostas que dão ao sofrimento, coproduzem o seu percurso), abre um leque formidável de possibilidades e probabilidades de transformação de todos os atores em relação.

Rotelli (1994) afirma que a desinstitucionalização denuncia e se opóe à necessidade de se conter no simples o complexo desigual, violentando-o no âmbito do saber, das regras e das práticas (ROTELLI, 1994). A desinstitucionalização opera uma ruptura da contenção e produz regras instáveis, portas abertas, cruzamento e circulaçáo de conhecimentos múltiplos que podem liberar os conflitos. Um processo de desestabilizaçáo capaz de criar as condiçóes para o desenvolvimento de uma crítica prática, de experiências de subjetivação e de multiplicação de papéis, saída da inércia subjetiva e institucional, numa reapropriação emocionante da riqueza singular de atores aptos a viver o jogo das trocas coletivas. Por que o que está em jogo na desinstitucionalização não é o manicômio, mas a doença; não é a instituição, mas o objeto da psiquiatria, aquele fenômeno produzido institucionalmente através dos saberes simplificados da nosografia psiquiátrica. As respostas institucionais do paradigma psiquiátrico tradicional, adequadas à noção de doença, não são apropriadas ao novo objeto, qual seja, a "[...] existência-sofrimento em sua relação com o corpo social." (ROTELLI, 1990, p. 90). Sáo táo pouco adequadas como seria um metro para medir um líquido, uma lente para ver toda a galáxia, ou uma caixa para conter um rio (ROTELLI, 1994). O problema será, portanto, não a doença, mas a emancipação; não a restituição da saúde, mas a invenção de saúde; não a reparação, mas a reprodução social, processos de singularização e ressingularização. $\mathrm{O}$ desafio é desinstitucionalizar as cenas que geram a violência e a exclusão, fazendo borbulhar possibilidades novas (ROTELLI, 1994). Complexidade do objeto, mutação do paradigma, projetos de transformação que produzam novos conhecimentos a partir da prática viva, do diálogo 
mais imprevisto e singular, da assunção de riscos, da mudança de valores, da polifonia de identidades, da produçãoo de vida. Pois a desinstitucionalizaçáo e a complexidade são partes de um mesmo processo, uma retroalimenta a outra. A desinstitucionalização vai tornando o fenômeno complexo e o ato de tornar complexo vai produzindo novas "instituiçóes de desinstitucionalização".

Assim, um novo paradigma é necessário. Mas o que seria esse novo paradigma? Segundo Morin (2002), o Ocidente possui um grande paradigma, formulado por Descartes no século XVII. Esse paradigma separa o sujeito do objeto, a filosofia da pesquisa reflexiva, a ciência da pesquisa objetiva. Essa dissociação se prolonga, atravessando o universo: sujeito-objeto; alma-corpo; espírito-matéria; qualidade-quantidade; finalidade-causalidade; sentimento-razão; liberdadedeterminismo; existência-essência (MORIN, 2002, p. 270). O paradigma do Ocidente tem seus conceitos soberanos e prescreve a relaçáo lógica, operando por disjunção.

A ciência, que se separou da filosofia no século XVII, obedecerá a um paradigma da simplificação, a uma visão determinista do universo. Eis então algumas características da ciência clássica: expulsão dos acasos e das desordens como epifenômenos ou efeitos da ignorância; simplicidade e fixidez; inércia da matéria submetida à especialização e geometrização do conhecimento; isolamento do objeto em relação ao seu ambiente e ao seu observador; inteligibilidade cartesiana (o que náo pode ser dito claramente deve ser excluído, silenciado); exclusão do não mensurável, não qualificável, não formalizável; redução da verdade científica à verdade matemática, reduzida à ordem lógica (MORIN, 2002). Desse modo, eliminam-se da "verdadeira" realidade todos os ingredientes de complexidade do real (sujeito, existência, desordem, acasos, qualidades, solidariedades, autonomias). Procede-se a uma visão por vezes atomística (que só vê unidades elementares) e/ou mecânica (que só vê uma ordem determinista simples).

Então, para se construir um novo paradigma apto a dialogar com um fenômeno complexo como o sofrimento psíquico é necessário conceber a complexidade do real usando as contradiçôes e a incerteza. Criar princípios e regras que estejam vinculados a um paradigma da complexidade, para usar a lógica sem se subjugar a ela (MORIN, 2002).

O paradigma psiquiátrico e seus dispositivos, dentre eles a laborterapia, desenvolveram-se no registro do paradigma cartesiano, operando à força simplificaçôes num fenômeno complexo como o do sofrimento psíquico. Sua desconstrução faz parte de um processo que visa tornar complexo o objeto de intervenção da psiquiatria, produzindo respostas adequadas às necessidades das pessoas, inclusive no que diz respeito a uma dimensão importante de nossa sociabilidade, a dimensão do trabalho.

Tendo como pano de fundo esse princípio e os conceitos de desinstitucionalização e de complexidade, o percurso metodológico deste trabalho se dará através de um breve relato do lugar que a laborterapia ocupou na psiquiatria para, posteriormente, caracterizar os projetos de trabalho e confrontá-los com essas práticas tradicionais. Pretende-se contribuir para a construção de um campo discursivo e de prática complexa que aponte novas possibilidades de intervenção em saúde mental a partir da desconstrução do paradigma psiquiátrico tradicional.

\section{A herança laborterápica}

O tratamento moral (FOUCAULT, 2005b; CASTEL, 1978) inventado pelos alienistas do século XIX manteve-se depois como uma assombração.

Mesmo tendo a psiquiatria do século XIX e XX enveredado pelo biologicismo, tentando legitimar-se como especialidade médica, à semelhança e com os mesmos métodos investigativos das outras especialidades focadas no corpo, o moralismo continuou como um fantasma pairando no ar, revelando-se o fim oculto das instituiçóes totais (GOFFMAN, 1974; BASAGLIA, 2001; CASTEL, 1977, 1978; FOUCAULT, 2000, 2005b).

O tratamento moral pôde atualizar-se em novas experiências com a conivência da psiquiatria orgânica, que tentava dissecar o cérebro para encontrar as causas das doenças mentais Uma dessas experiências foi a da terapêutica ativa de Herman Simon (DE CARLO; BARTALOTTI, 2001; AMARANTE, 1995; BIRMAN, 1992). Ela nasceu quando o psiquiatra viu a necessidade de colocar os próprios pacientes para trabalhar na reconstruçáo de um hospital destruído pela guerra e percebeu que eles melhoravam, que o envolvimento com a tarefa tomava o lugar dos pensamentos mórbidos. Ou seja, trágica ironia, os pacientes ficavam melhores utilizando sua energia para reconstruir a instituição que iria destruí-los, vetando sua participação na vida social. É verdade que o objetivo da ação era o que menos importava; poderiam também carregar pedras de um lado para outro, construir montes que seriam desmontados tão logo fossem elevados que o efeito talvez fosse o mesmo. Talvez tenha ressurgido daí o termo ocupação, tautologia do fim em si mesmo, da produção do não sentido, da alienação. 
O segundo retorno do fantasma do tratamento moral, que pôde deixar de ser latente para ser manifesto, no nosso caso brasileiro, veio à tona com os alienistas do fim do século XIX e início do XX. Em sua aliança com os higienistas e com os eugenistas, os grandes psiquiatras desse tempo construíram seu reino em imensos terrenos afastados das cidades, onde foram instaladas as grandes colônias (agrícolas, mas não só). O lema desses locais era trabalho, trabalho e trabalho. Disciplina e moral rondavam o cotidiano dos internos, que podiam chegar aos milhares, como foi o caso do Juqueri do Dr. Franco da Rocha (CUNHA, 1990). Além da ocupação, reinava a forte exploração, pois o que os internos recebiam como fruto do trabalho era apenas a possibilidade de se alienarem e se manterem reclusos, tornando as instituiçốes de segregação quase autossustentáveis economicamente.

Com a modernização da psiquiatria no Brasil, somando-se às influências dos alienistas da Europa (os nossos alienistas foram formados por eles), o biologicismo contribuiu para fazer uma síntese entre as práticas disciplinares e aquelas mais científicas que, com sua expertise, ajudaram a queimar de forma violenta muitos neurônios e, de certa forma, mantêm-se assim até hoje, como atesta a situação de muitos dos hospitais psiquiátricos que ainda sobrevivem ao movimento da reforma psiquiátrica (KINKER, 2007).

O tratamento moral manteve sua presença fantasmática, produzindo novas roupagens e descendentes sempre mais modernos. Nos termos de Castel (1978), houve um verdadeiro aggiornamento, uma modernização, uma atualização.

Algumas cenas mais recentes demonstram isso: a presença de um visgo moral mesmo nas experiências europeias e americanas de reforma psiquiátrica do pós-guerra, a invenção da profissão terapia ocupacional como redentora e humanizadora dos hospitais psiquiátricos no início do século XX, nos EUA, anos mais tarde na Europa e nos anos 1950 no Brasil (DE CARLO; BARTALOTTI, 2001).

Essas tecnologias disciplinares também foram sendo transportadas para a lida com outros desviantes: pessoas com deficiências, idosos, tendo como espaço privilegiado de intervenção as instituições totais e produzindo toda sorte de estigmas (GOFFMAN, 1974, 1980).

As práticas laborterápicas baseiam-se na produção de corpos dóceis (FOUCAULT, 2000; EWALD, 1993), no treinamento de hábitos de trabalho, de comportamentos adequados, limitados e subservientes, nada questionadores. A partir delas foram desenvolvidos programas de treinamento para a futura inserção no mercado, ou formas mais ou menos veladas de exploração e de enrijecimento de possibilidades: assim o eram os contratos de empresas - comuns ainda nos anos 1980 - que destinavam parte do processo produtivo a instituiçôes que atendiam pessoas com deficiência mental (por exemplo, a montagem de pregadores de roupa, de bolas de futebol ou de outros produtos de confecção simples). Tais práticas, que eram muito mal remuneradas, pois se considerava esse um trabalho de segunda linha que mais ajudava as pessoas com deficiência do que as empresas, não permitiam que os trabalhadores se apropriassem do processo de trabalho, muito menos do valor gerado por ele. Muitos trabalhadores nem sabiam o quanto recebiam e náo tinham a menor ideia do processo em que estavam envolvidos (por exercitarem pouco as trocas sociais, também sabiam pouco a respeito do que seria possível realizar com seus rendimentos). Apenas os profissionais das instituiçôes é que se apropriavam das informaçóes e tomavam as decisóes, já que, a priori, os trabalhadores eram considerados incapazes de responder por si. Não se investia nas capacidades e potencialidades dos trabalhadores e apenas se reforçava sua limitação perante um contexto estéril de possibilidades.

A relação da proposta laborterápica com os outros atores sociais sempre reforçou e legitimou a incapacidade e a invalidez daqueles que eram treinados, fortalecendo a ideia de que os espaços possíveis de vida e de troca seriam apenas as instituiçôes de reabilitação. Fossem monitores de ofício a lidar com os aprendizes, fossem os empresários que filantropicamente lhes designassem alguma tarefa simples como parte da produção, as mensagens emitidas e reforçadas sempre foram a do limite, a da insuficiência, já que não se questionavam os contextos e as normas.

Atualmente, ainda com base na tecnologia do treinamento de hábitos de trabalho, desenvolvem-se em várias instituiçôes programas de inserção no emprego, aproveitando-se da brecha que obriga as empresas a contratarem certo percentual de pessoas com deficiências. Essas inserçôes, mais uma vez, por serem individuais e por muitas vezes não envolverem funçôes reais e necessárias, sendo voltadas apenas para a resolução dos problemas das empresas com as leis, acabam reforçando o aspecto estigmatizante e discriminatório de incapacidade, imaturidade, invalidez das pessoas que possuem alguma deficiência. O caráter de invalidez está no próprio fato de essas pessoas muitas vezes serem desnecessárias às organizações. A prática de preparação para a 
futura inserção no trabalho, através do treino de habilidades e de hábitos de trabalho, revelou sua obscura perversidade: com o passar dos anos, foi se tornando perceptível que poucos eram os considerados plenamente reabilitados e inseridos realmente no trabalho. $\mathrm{O}$ treino para a futura inserção laboral foi deixando de ser uma etapa para se constituir num momento perene e eterno de exclusão e controle.

Em resumo, no que diz respeito à história da psiquiatria, seja sob uma forma de entretenimento (SARACENO, 1999a, 2001)2 , normalização, adestramento, disciplina (FOUCAULT, 2000, 2005a; CASTEL, 1978), exploração do trabalho, diminuição dos custos das instituiçôes, a justificada terapia pelo trabalho dentro do hospital psiquiátrico gerou toda sorte de perversóes e exercícios de micropoderes e opressões que se iniciaram a partir das próprias relaçóes entre os internos, reproduzindo a lógica de poder que tem no médico o modelo do poder moral $^{3}$ (FOUCAULT, 2005b).

\section{Projetos coletivos de trabalho como desconstrutores do paradigma psiquiátrico}

\subsection{A implantação do núcleo do trabalho}

No Hospital Anchieta de Santos, antes da intervenção municipal, alguns internos diferenciavam-se dos demais, chegando-se a definir, dentre os pacientes mais desobedientes, aqueles que deveriam permanecer nas celas fortes e aqueles que deveriam ser submetidos à ECT (eletroconvulsoterapia). Os laborterápicos eram essas personagens responsáveis tanto pela vigilância quanto pela manutenção do hospital em áreas como limpeza e alimentação. Nitidamente, cumpriam a função de poder que os alçava a um grau ascendente de valorização e diferenciaçáo perante os demais internos, o que possivelmente explicava o fato de não quererem sair do hospital para construir um projeto de vida. Recebiam para tanto algumas regalias como cigarros ou um prato de comida especial.

Foi por conta dos laborterápicos, também, que se pensou, num primeiro momento, em designar alguns profissionais da equipe do hospital para discutir-se a questão do trabalho. Foi então que nasceu o Núcleo do Trabalho, com o objetivo de desenvolver projetos que se confrontassem com o mercado. É da história do Núcleo e dos projetos de trabalho que se tratará a seguir.
O Núcleo do Trabalho, transformado em Unidade de Reabilitação Psicossocial em 1992, era uma equipe constituída por quatro terapeutas ocupacionais, dois psicólogos, dois assistentes sociais, uma artista plástica, três monitores de ofício, dois funcionários administrativos e um auxiliar de enfermagem. Envolveu cerca de 150 usuários-trabalhadores divididos entre dez projetos coletivos de trabalho. Cerca de metade deles recebiam bolsas de trabalho no valor de 1,5 salário-mínimo para trabalhar em grupo durante seis horas diárias nos projetos, em parceria com as secretarias municipais e empresas públicas que pagavam as bolsas; a outra metade prestava serviços ou vendia produtos e dividia o que arrecadavam, resultando numa quantia entre um terço de salário-mínimo e dois saláriosmínimos para cada usuário-trabalhador, para uma carga horária de trabalho que variava entre oito e 30 horas semanais. Através de um processo de reconversão de recursos, que deixavam de ser gastos na manutenção do manicômio, a Secretaria de Higiene e Saúde do município investia em equipamentos de trabalho, automóveis e recursos humanos para o desenvolvimento dos projetos. A parceria com outras instituiçóes públicas e privadas, o envolvimento com os movimentos populares do cooperativismo, o protagonismo dos usuários-trabalhadores no desenvolvimento dos projetos de trabalho foram marcas importantes dessa experiência.

Foi assim que se iniciaram experiências de trabalho coletivo, todas com a denominaçáo comum de Projetos, como a triagem de materiais recicláveis (em parceria com a empresa mista Prodesan, responsável pela limpeza urbana da cidade), os serviços de jardinagem em praças públicas e terrenos particulares (em parceria com a Secretaria do Meio Ambiente, o Jardim Botânico e empresas privadas que financiavam a atividade com o intuito de afixar propaganda nas praças), os serviços de desinfecçáo de reservatórios de água (em parceria com a Vigilância Sanitária), a marcenaria, o grupo de culinária, o grupo de serigrafia, a equipe de manutenção predial (em parceria com a Companhia Santista de Transportes Coletivos), a fábrica de blocos de construção, o grupo de construção civil (ambos em parceria com a Cohab santista), o projeto de venda de produtos apícolas em feiras livres e praças públicas (em parceria com a Secretaria de Abastecimento), entre outros projetos (alguns mais exitosos, outros menos), todos gerando recursos econômicos. As diversas secretarias municipais passaram a contribuir disponibilizando o trabalho de seus profissionais, fazendo contato com empresas para propor projetos em parceria, emprestando equipamentos e insumos, como terra 
adubada, caminhóes, ferramentas de jardinagem, máquinas de produção de blocos para a construção civil, bombas de sucção para esvaziamento de caixas d'água etc. Essas alianças com as secretarias possibilitariam, no futuro, a ampliação do arco de alianças com outros atores sociais, desde empresas privadas até movimentos sociais.

\subsection{Princípios dos projetos de trabalho}

Os profissionais, os gestores e os voluntários envolvidos no processo de intervenção no Anchieta sempre pensaram que seria preciso modificar algo na relação com o mercado para que os internos pudessem exercer seu direito e escolha de trabalhar.

Acredito que isso se deva ao fato de passarmos a nos comunicar de outra forma com os usuários, superando os filtros pautados pela nosografia psiquiátrica e pela doença, de modo que esses encontros nos permitiam o acesso a necessidades antes tornadas irrelevantes e inexistentes (BASAGLIA; BASAGLIA, 1977).

Não era mais o discurso nosográfico da psiquiatria que diria o que eles sentiam e queriam ou o que eram capazes de fazer. A desconstrução desses conceitos e valores se deu na trama de relaçóes intensas e de mútuas afetaçôes (SPINOZA, 2009) que formavam novos conceitos e valores.

Aqui, o trabalho podia ser visto como uma das muitas possibilidades de participar das cenas sociais, de dar novos sentidos às contradiçôes sociais que produziam até mesmo as instituiçóes totais como agências produtoras de controle disciplinar e violento.

Mas não poderia ser qualquer trabalho, o mercado, com suas injunçôes, há muito já enunciou que não há lugar para os loucos a não ser no manicômio. $\mathrm{O}$ modo de vida que orbita a forma moderna de trabalho é o da racionalidade utilitária, que joga para a margem ou tenta dizimar tudo aquilo que não segue o paradigma da simplificação (MORIN, 2001), do empobrecimento de possibilidades. O mundo do trabalho é a antítese do mundo da loucura e tentar adaptar e normalizar os internos para que possam ser artificialmente encaixados no mercado pode acabar tornando-se uma ilusão. Além do mais, é preciso questionar se é desejável participar de um mundo do trabalho que é pura tautologia e que vive para a reproduçáo abstrata do capital e para a ensandecida circulação de mercadorias.

Foi por isso que decidimos produzir experiências ricas em termos de produçáo de sociabilidade, valores, relaçôes, poder que deveriam forjar situações reais de trabalho coletivo, vinculadas efetivamente ao mercado.

Mas a participação no mercado deveria possibilitar que a produção de valor, mercadoria e dinheiro liberasse a produçáo de vida e de sociabilidade, através da crítica cotidiana da sociabilidade empobrecedora do trabalho e da centralidade abstrata da mercadoria nas relaçóes sociais.

Seria preciso recusar uma inserção subserviente ao mercado e aos processos de normalizaçáo e adaptação daí decorrentes. O que se buscava eram modificaçôes negociadas e de mão dupla: transformaçōes nos usuários-trabalhadores através do exercício do poder e da descoberta de novas potencialidades e formas inéditas de produzir e transformações nos contextos de trabalho e no próprio mercado, produzindo novos contextos acolhedores e ao mesmo tempo desafiadores.

Os projetos coletivos de trabalho questionavam as formas fixas e autoritárias de se fazer as coisas. Participar de um projeto era produzir espaços de pertencimento e de acolhimento que fossem terreno propício para a descoberta de potencialidades e para o exercício de poder. Era produzir espaços potentes e consolidados de enfrentamento de desafios e riscos que representassem efetivamente modificaçóes nos fluxos de poder, mudanças concretas e subjetivas (na forma de se relacionar e de estar no mundo, e no acesso a bens e serviços), iniciando percursos coletivos que seguiam produzindo uma multiplicidade de possibilidades.

Isso exigia que os usuários-trabalhadores assumissem novos papéis e identidades múltiplas, redefinindo e somando outras identidades à sua histórica identidade de pacientes. Tal processo exigia também que os profissionais de saúde mental tornassem múltiplas as suas funções de cuidadoresterapeutas e as redefinissem, possibilitando que os outros atores sociais também revissem sua forma empobrecida de estar no mundo.

Era isso, não haveria como transformar os internos sem transformar a sociedade e seus valores e sem que também fossem transformados os papéis dos que receberam a delegação social de cuidar e de proteger, mas também de controlar (CASTEL, 1977) - o que, em última instância, significava segregar, separar, destruir -, ou seja, os técnicos de saúde mental.

Agora o novo papel dos técnicos deveria ser adentrar os espaços sociais junto com os usuários, mediando relaçóes, possibilitando que eles fossem protagonistas de transformaçóes e, assim, encontrassem outro lugar no mundo. 
Para isso ser alcançado cotidianamente, fazia-se necessário multiplicar os atores envolvidos, de forma que esse diálogo não se resumisse apenas aos representantes da psiquiatria e da saúde mental e aos internos de quem deveríamos cuidar. A potencialidade desse recurso - o envolvimento de outros atores de fora do campo da saúde mental - residia na possibilidade de transformação dos próprios atores envolvidos, ou seja, quando os atores de fora do campo da saúde mental, bem como os técnicos, se sentissem em processo de transformação, então os usuários dos serviços de saúde mental também estariam se transformando. $\mathrm{O}$ envolvimento de jardineiros, engenheiros agrônomos, marceneiros, engenheiros civis, operários, administradores, artistas, entre outros cedidos pelas secretarias municipais que participavam dando apoio concreto cotidianamente na realização do trabalho dos usuários permitiu a tomada do trajeto contrário ao das práticas laborterápicas, abrindo possibilidades através da qualificação do trabalho, da descoberta de formas coletivas de venda de produtos e serviços com garantia de qualidade.

Uma das estratégias da implantação dos projetos de trabalho foi priorizar a escolha de atividades produtivas diversificadas, definidas a partir da identificação de necessidades e brechas do mercado e das possibilidades de se levantar recursos (humanos, materiais, parcerias) para o seu desenvolvimento (KINKER, 1997). Essa diversidade servia para ampliar as possibilidades de escolha e de inserção participativa. A entrada dos usuários nos projetos de trabalho não se baseava no esquadrinhamento de seu diagnóstico clínico, mas, partia de sua biografia, da prospecção de suas capacidades, expectativas e possibilidades (NICÁCIO; KINKER, 1996).

A multiplicidade de projetos estava associada também à multiplicação de experiências e ao fortalecimento do protagonismo. Inversamente ao que as tradicionais práticas laborterápicas propóem. Nesse caso, as pessoas com sofrimento psíquico grave, além de poderem ter maior liberdade para se experimentar em tarefas e lugares diferentes, podiam exercer poder decisório e ser protagonistas dos processos de trabalho. A construção de projetos passava a depender essencialmente da participação dos usuários-trabalhadores. Os projetos não ocorriam apesar deles, como se pode verificar nas instituiçóes que reproduzem o controle social do desvio, mantendo seus clientes dentro de certos limites e em áreas com pouca possibilidade de circulação, experimentação e exercício de poder (SARACENO, 1999b).

Não seria bem-vindo um processo que empregasse os usuários no trabalho apenas por filantropia, nem tampouco que desacreditasse de suas reais capacidades. Nem seria aceito um tipo de relaçáo que colocasse o trabalho dos usuários como uma concessão definida pelo governo municipal. Fugíamos da possibilidade de criar situações artificiais, onde se fingisse estar trabalhando, onde se fingisse estar consumindo e necessitando desse trabalho, onde os usuários fossem tratados como inválidos e incapazes de responder por si.

Queríamos que o trabalho fosse real e que seu consumo e uso fossem necessários. Que possuísse qualidade e que, ao mesmo tempo, garantisse o modo singular de estar no mundo de seus trabalhadores. Queríamos reproduzir situaçóes de trabalho em equipe similares às que nós, enquanto equipes de saúde mental, vivenciávamos. Situaçóes onde coubessem nossas singularidades, dificuldades e potencialidades.

No decorrer da constituiçáo dos projetos de trabalho foi possível estabelecer uma dinâmica de protagonismo e participação efetiva dos trabalhadores em todos os seus aspectos e dimensóes. As reunióes semanais com toda a equipe do projeto eram espaços de troca e de constituição de um projeto coletivo, onde as conquistas eram comemoradas, as dificuldades, discutidas solidariamente, as contradiçóes, debatidas, as perspectivas futuras, compartilhadas e projetadas coletivamente. A ideia era que a plasticidade das estratégias permitisse que usuários com sofrimento psíquico muito grave pudessem exercer níveis variados de protagonismo. As dificuldades na viabilização do trabalho de pessoas com sofrimento psíquico grave colocavam novos desafios, já que geralmente tais dificuldades estavam no contexto e náo nas pessoas, o que trazia a necessidade de se pensar em estratégias inovadoras de facilitaçáo do trabalho. Sendo assim, mediação e negociação eram as palavras-chave do trabalho no Núcleo, bem como ação, continência, tolerância, espírito crítico, reflexão, contextualização, transformação.

Os recursos econômicos gerados com a participação nos projetos possibilitaram que pacientes há muito institucionalizados no hospital psiquiátrico pudessem retomar a construção de sua vida na cidade, pagando do próprio bolso os custos de moradia, transporte, alimentação, lazer, vestuário. Possibilitaram também novos diálogos com as famílias, que passaram a ver seu familiar portador de sofrimento psíquico como alguém capaz de contribuir significativamente com as despesas da casa, ocupando outro lugar nas relaçóes familiares.

É claro que esse percurso foi gradual e repleto de desafios, exigindo dos profissionais do Núcleo do Trabalho, em conjunto com os dos Núcleos de Atenção Psicossocial, um investimento intenso no 
acompanhamento e na mediação dos usuários em sua relaçáo com o trabalho e com todos os atores desse contexto: desde a saída no começo da manhá, para ir junto com os usuários iniciar o trajeto para a ocupação dos postos de trabalho, até que eles se sentissem fortalecidos para fazê-lo sozinhos, e também no apoio para a organização dos usuários enquanto equipes de trabalho e, muitas vezes, na organização cotidiana de seus novos lugares de existência, casa, pensão.

O contato e a construção cotidiana com os Naps permitiam que a equipe do Núcleo participasse efetivamente da construção de um Sistema de Saúde Mental que pouco a pouco levaria à substituição total do manicômio. Construía-se uma base de conhecimentos coletivos que aprofundavam as táticas de multiplicação das redes sociais, bem como fortaleciam a descoberta de novas possibilidades e recursos comunitários.

Essa integração se dava através de atendimentos, visitas aos locais de trabalho ou de moradia realizadas conjuntamente pelas duas equipes, atendimentos familiares, quando necessário, e, principalmente, através de reuniôes frequentes entre membros das duas equipes, para avaliar o trabalho e pensar em estratégias conjuntas de intervenção.

Em princípio, a equipe do Núcleo se encarregava prioritariamente de viabilizar e acompanhar os projetos de trabalho através de visitas aos locais e reuniôes de trabalho, enquanto as equipes dos Naps teciam junto ao usuário o sentido de seu projeto de vida em seus outros âmbitos ${ }^{4}$. O lugar dos projetos de trabalho era organicamente vinculado aos vários serviços de saúde mental, o que permitia superar a artificial separação entre lugar de tratamento, lugar de reabilitação, lugar de prevenção e lugar de produção de vida. Estar trabalhando não significava um momento posterior ao tratamento, muito menos sinal de cura, mas a possibilidade de ampliar o arco de relaçóes, descobrir e exercer potencialidades, tecer uma condição de vida e uma de relaçóes sociais que fossem produtoras constantes de subjetividade.

Aqui, o objetivo de todos era mediar relaçóes e apoiar os usuários na construção de seus projetos de vida e na tessitura concreta de novas redes sociais. $\mathrm{O}$ objetivo não era lidar com a doença, mas com a produção de vida, intensidades que todas as pessoas experimentam quando estáo buscando aumentar sua "potência de agir" (SPINOZA, 2009)5 Buscava-se viver o mais ricamente possível, num devir (DELEUZE; GUATTARI, 1997, 2004) permanente de transformaçóes de contextos e subjetividades.
Em nossa perspectiva, entretanto, o trabalho não se colocava como o dispositivo único e obrigatório de inserção social ou reabilitação, não era o lugar obrigatório por onde todos os usuários deveriam passar. Não estava destinado aos pacientes "menos graves", nem era visto como um momento posterior do que se considerava tratamento terapêutico. A participação num projeto de trabalho era uma possibilidade de ampliaçâoo da rede social e do arco de relaçôes pessoais dos usuários; uma possibilidade entre outras, podendo ser utilizada desde que produzisse sentido para o processo do usuário na construção de seu projeto de vida. Náo poderia ser o único caminho para a produçáo de poder de contrato nem valor social, já que vivemos um momento muito especial do mundo do trabalho, momento em que existe a possibilidade de se inventarem novas formas de atividade humana que produzam sentido no bojo dos resultados da revolução microeletrônica.

A iniciativa de ocupar múltiplos espaços sociais é outra característica que diferencia os projetos coletivos de trabalho das propostas laborterápicas. A noção de lugar/local específico para a prática de reabilitação é questionada, uma vez que o que se buscava era a multiplicação de espaços e possibilidades, era a abertura e não o fechamento. Estando os projetos localizados em vários lugares diferentes, era possível propor o convívio e o compartilhamento de espaços, numa nova relação entre o que é considerado normal e anormal. Essa dicotomia era superada concretamente no exercício artesanal de tecer novos territórios e novas alianças.

Ocupando outro lugar social, os usuáriostrabalhadores passavam a fazer parte do cotidiano da cidade, desenvolvendo açóes que os ligavam uns aos outros e os faziam cuidar das outras pessoas. Bela reciprocidade de papéis, uma vez que aqui os ditos anormais também cuidavam dos normais, cuidando das praças, desinfetando as caixas d'água das unidades de saúde, construindo casas populares, fabricando blocos para a construçáo civil, separando o material reciclável na usina de triagem para preservar o meio ambiente e o aterro sanitário já saturado.

Tentávamos optar pelo desenvolvimento de atividades que eram repletas de riscos e desafios (KINKER, 1997).

Arriscar-se por algo é o que pode dar sentido às açốes. Superar o medo dos riscos é uma tarefa cotidiana dos profissionais de saúde mental e não é nada simples. Mas ela traz consigo a possibilidade de modificar os fluxos de poder e saber e, dessa forma, modificar os contextos, os papéis e as hierarquias. 
Tentávamos manter o equilíbrio possível na medição dos riscos, sabendo que os desafios eram imprescindíveis. Medindo os riscos, assumimos com os usuários alguns percursos imprevisíveis. Esse estar no mundo é muito diferente da vivência negativa e anulada de ser um interno de uma instituiçáo total, ou de ser um participante de um programa de laborterapia numa oficina protegida.

Um exemplo da assunção de riscos foi a decisão de implantar a Fábrica de Blocos em Bertioga, localizada a mais de 40 quilômetros do centro de Santos, o que exigia que nos deslocássemos e mantivéssemos os usuários-trabalhadores longe da maioria dos recursos de suporte oferecidos pela cidade de Santos.

Muitas vezes essa situação dificultou nossa ação, mas quando assumimos o projeto avaliamos que deveríamos aproveitar a oportunidade. Acredito que tenha sido uma escolha correta, pois foi um aprendizado intenso para a equipe e para os usuários. Além disso, nossa ida para a Fábrica de Blocos deu início à implantação de uma equipe de saúde mental que passou a atender a populaçáo local, algo que até então não ocorria.

A escolha da cooperativa de trabalho como instância de representação dos usuários e demais envolvidos nas relações estabelecidas com o mercado foi também uma das marcas do processo santista.

A cooperativa era uma pessoa jurídica formalmente constituída, que deveria nesse caso possuir alianças com diversos setores da sociedade, permitindo sua forte inserção no mercado e, ao mesmo tempo, desenvolvendo projetos que incorporassem intervençóes inovadoras na cidade, em busca de uma cidade mais saudável.

Esses projetos que envolviam trabalho, alianças sociais e projetos inovadores tentavam criar as condiçôes para a composição dos empreendimentos sociais, como defendem os italianos (GALLIO, 1991) $)^{6}$.

A cooperativa era uma opção política de organização do trabalho que rechaçava as situaçôes de exploração e criava entre os trabalhadores vínculos que ultrapassavam o compromisso com a produção.

A intenção de que a comunidade local se envolvesse para se tornar cúmplice, corresponsável e participante ativa do processo e do sucesso da cooperativa, que passaria a ter características de empreendimento social, com perfil ao mesmo tempo público e privado, abria espaços para a produção de valores que contradiziam o movimento do mercado e do capital.
Esses laços propunham o desenvolvimento sustentado da cidade, compatibilizando desenvolvimento econômico e bom senso na preservação da natureza e do bem-estar da população, desqualificando preconceitos e processos de exclusão.

É que aqui também os valores de periculosidade e incapacidade dos loucos podiam ser fortemente enfrentados.

Mas constituir uma cooperativa composta por pessoas que são consideradas incapazes pelo código civil (que sempre utilizou a nosografia psiquiátrica como base de apoio) é algo que contradiz os pressupostos básicos de incapacidade em que se apoiam os diagnósticos psiquiátricos.

De fato, a relação entre a psiquiatria e a justiça é antiga e data da época do nascimento da primeira, que auxiliou a justiça na difícil tarefa de ter que interditar pessoas em pleno momento histórico de defesa dos direitos individuais (CASTEL, 1978; FOUCAULT, 2002, 2006).

E não foi diferente quando da constituiçáo da cooperativa. Na época, alguns advogados consultados, por exemplo, assinalaram que a constituição da cooperativa poderia ser ilegal. Sempre rebatemos esse posicionamento dizendo que boa parte dos usuáriostrabalhadores não eram interditados oficialmente e que, sendo assim, poderiam responder por si, mesmo que precisassem de apoio. Da mesma forma, poderiam responder conosco formalmente pela cooperativa. E foi assim que fizemos.

A cooperativa enfrentou muitos desafios em seu início e até o momento em que pude acompanhá-la. Embora fosse uma construção recente e frágil, ela tentou se constituir como um espaço de protagonismo e decisão dos usuários-trabalhadores, que passaram a ser reconhecidos como cooperados. Essa construção exigiu que se agenciassem espaços de alfabetização e problematização do cotidiano, numa perspectiva construtivista, o que foi constituído com a contribuição da Secretaria de Educação.

A trajetória do Núcleo do Trabalho evidenciou que as transformaçóes dos paradigmas e das formas concretas de vida exigem constante energia, alimento, investimento. Sabíamos que nadávamos contra a maré, à beira-mar, e que essa pequena construção fazia parte de uma importante e potente obra de intervenção na cidade, nas mais variadas áreas, que transformaram a vida de muitos e marcaram para sempre os corpos e as mentes daqueles que participaram ativamente desse processo. 


\section{Conclusão: A superação das práticas laborterápicas e a produção de novas sociabilidades}

No percurso deste artigo, a palavra laborterapia apareceu muitas vezes. Ela surge com a constituição da própria psiquiatria, embora não fosse nomeada dessa forma.

Desde seu início, a psiquiatria foi um importante instrumento da sociabilidade do trabalho e a ela se atrelou cada vez mais intensamente, como revela a multiplicação dos códigos da nosografia. Desconstruir o paradigma psiquiátrico remete, desse modo, à desconstruçáo da sociabilidade do trabalho e, portanto, à desconstruçáo do mercado e da mercadoria.

Quis apontar essas diferenças desde o início, para que fique claro que a proposta dos projetos coletivos de trabalho não é uma atualização da terapia pelo trabalho. O que se quer questionar é muito mais do que uma técnica específica que utiliza a questáo do trabalho em práticas de cuidado. $\mathrm{O}$ que se quer questionar é a própria noção de cuidado, de terapêutico que constitui o paradigma psiquiátrico. O cuidar, nessa perspectiva, está indissociado do processo de construção de novas formas de sociabilidade.

É por isso que a expressão projetos de trabalho ganha forte conotação e é utilizada no lugar de outras como oficina, grupo terapêutico, ergo ou laborterapia. O termo projeto indica o protagonismo e a projetualidade que caracterizam qualquer processo de transformação.

Os projetos de trabalho contradizem as práticas laborterápicas pelos seguintes elementos:

- Proposta e possibilidade de circular por dentro e por fora do mercado, numa linha tênue que nunca poderia explodir. Esse trânsito significava criar situaçóes reais de trabalho e inocular transformações no mercado, ao invés de ocupar uma posição subalterna e alienante comum nas práticas laborterápicas apoiadas na invalidez, na incapacidade e na suposta ausência de capacidades de exercer os direitos civis de seus usuários.

- Negação dos processos de normalização e adaptação realizados através do adestramento de comportamentos esperados e do treino de hábitos de trabalho. $\mathrm{O}$ que se buscava era questionar as formas estandardizadas e padronizadas de se fazer as coisas e de se relacionar, geralmente de forma subalterna e sem questionar as normas.

- Produção de lugares potencializadores de capacidades, que exigiam modificaçôes negociadas entre todas as partes: usuários, profissionais de saúde mental e contextos, produzindo lugares ao mesmo tempo acolhedores e desafiadores. O exercício do diálogo entre as potencialidades/possibilidades dos usuários e as potencialidades/possibilidades dos contextos foi uma forma de escapar das formas limitadas, empobrecidas e incapacitantes dos contextos laborterápicos.

- Negação da exploração econômica comum nas práticas das oficinas protegidas.

- Forma singular de envolver outros atores externos ao campo de saúde mental. Nas práticas laborterápicas, os atores externos (fossem empresários a contratar os serviços dos usuários, fossem monitores de ofício) eram inseridos através do paradigma da anormalidade e da incapacidade e, por isso, viam-se participando de projetos beneficentes que manteriam os usuários nas mesmas condiçôes de subalternidade e invalidação. Nas práticas dos projetos de trabalho, os atores envolvidos foram levados a um tipo de relação que lhes possibilitava modificar o olhar sobre os fenômenos e sofrer eles mesmos, assim, transformaçóes na forma de ver o mundo e de lidar com a vida. Essas mudanças nas relaçóes de poder/saber é que produziam transformações.

- Busca constante da qualidade dos bens e dos serviços produzidos, através de estratégias singulares de produção e da participação de especialistas e profissionais externos à área de saúde mental. Essa busca por qualidade, que permite a relação real com o mercado, ultrapassa a ideia de que pessoas em desvantagem social só podem fabricar artigos para bazares de instituiçôes filantrópicas, que serão adquiridos como forma de ajuda e não por necessidade daqueles que usarão os produtos (além de a renda obtida ser utilizada para a manutenção da instituiçáo, configurando-se também uma situação de exploração).

- Negação da nosografia psiquiátrica como fator determinante para a inserção nos projetos de trabalho, trocando-a pela biografia dos usuários, 
por suas expectativas e desejos, bem como por suas possibilidades.

- Constituição dos projetos de trabalho como alternativas reais para a reprodução da vida dos usuários na cidade, dando-lhes condiçôes de pagarem do próprio bolso suas despesas com moradia, alimentação, vestuário etc., de modo que eles dependam das instituiçóes de outra forma (dependam de seu apoio para enfrentar o desafio prazeroso de viver livremente nas cidades, em meio às contradiçôes sociais).

- Superaçáo, através de um processo cotidiano de mediação na descoberta de potencialidades e na produção de autonomia, das noçốes estanques de espaço de tratamento, espaço de reabilitação, espaço de vida, exercício de direitos. O trabalho não seria mais, como nas práticas laborterápicas, o lugar e o momento da reabilitação, posterior ao tratamento e próximo à cura, pois náo se lidava tendo como referência a doença, mas sim a existência-sofrimento em sua relação com o corpo social (ROTELLI, 1990).

- Multiplicaçáo e abertura dos espaços de realização do trabalho, em contraposiçáo à limitação e ao fechamento de espaços propiciados pelas práticas laborterápicas. Os projetos de trabalho não são apenas de trabalho, mas projetos de intervenção cultural e de produção de novas mensagens ao imaginário social.

- Fundamentação dos projetos no protagonismo e no exercício de poder dos usuários, buscando a constituição da cooperativa como representação jurídica no mercado. Essa opçáo exigiu o enfrentamento das noçôes jurídicas de incapacidade civil atribuídas aos usuários, nas quais se basearam historicamente a psiquiatria e suas práticas laborterápicas.

Para que a reforma psiquiátrica avance se faz necessária a produçáo de estratégias que ampliem efetivamente a rede de relaçóes e as experimentações dos usuários dos serviços.

A necessária ruptura epistemológica e prática na relação com a loucura implica descartar muitos dos conhecimentos até aqui estabelecidos para que dessa desconstrução surjam novos arcabouços teóricos e práticos capazes de lidar com um objeto táo complexo e incerto como o sofrimento psíquico.

Desinstitucionalizar o paradigma psiquiátrico significa desinstitucionalizar o mercado e a nós mesmos, produzindo novos modos de viver e relacionar-se.

\section{Referências}

AMARANTE, P. (Org.). Loucos pela vida: A trajetória da reforma psiquiátrica no Brasil. Rio de Janeiro: SDE/ ENSP, 1995.

BASAGLIA, F. As instituições da violência. In: BASAGLIA, F. (Org.). A instituição negada. Tradução de Heloísa Jahn. 3. ed. Rio de Janeiro: Graal, 2001. p. 99-133.

BASAGLIA, F.; BASAGLIA, F. O. Los crímenes de la paz. In: BASAGLIA, F.; BASAGLIA, F. O. (Orgs.). Los crimenes de la paz: Investigación sobre los intelectuales y los técnicos como servidores de la opresión. Tradução de Juan Diego Castillo con la colaboración de Maria Elena Petrilli y Marta E. Ortiz. Revisión técnica de Armando Suárez. Madrid: Siglo XXI de España, 1977. p. 13-102. BIRMAN, J. A cidadania tresloucada. In: BEZERRA, B.; AMARANTE, P. (Org.). Psiquiatria sem hospicio: Contribuiçóes ao estudo da reforma psiquiátrica. Rio de Janeiro: Relume-Dumará, 1992. p. 71-90.

CAPISTRANO FILHO, D. A casa dos horrores. In: CAPISTRANO FILHO, D. Da saúde e das cidades. São Paulo: Hucitec, 1995. p. 99-120.

CAPISTRANO FILHO, D.; KINOSHITA, R. T. O Programa de Saúde Mental da cidade de Santos, Brasil. In: ORGANIZAÇÁO PANAMERICANA DA SAÚDE. Reestruturaçâo da assistência psiquiátrica: bases conceituais e caminhos para sua implementação. Caracas, Conferência Regional, 11-14 nov. 1990. Brasília: Programa de Prevenção de Saúde, 1992. p. 20-22.

CASTEL, R. La contradicción psiquiátrica. In: BASAGLIA, F.; BASAGLIA, F. O. (Orgs.). Los crimenes de la paz: Investigación sobre los intelectuales y los técnicos como servidores de la opresión. Tradução de Juan Diego Castillo con la colaboración de Maria Elena Petrilli y Marta E. Ortiz. Revisión técnica de Armando Suárez. Madrid: Siglo XXI de España, 1977. p. 151-66.

CASTEL, R. A ordem psiquiátrica: A idade de ouro do alienismo. Tradução de Maria Thereza da Costa Albuquerque. Rio de Janeiro: Graal, 1978.

CUNHA, M. C. P. Cidadelas da ordem: A doença mental na República. Sáo Paulo: Brasiliense, 1990.

DE CARLO, M. R. P.; BARTALOTTI, C. C. (Orgs.). Caminhos da Terapia Ocupacional. In: DE CARLO, M. R. P.; BARTALOTTI, C. C. (Orgs.). Terapia Ocupacional no Brasil. São Paulo: Plexus, 2001. PMCid:PMC101159.

DELEUZE, G.; GUATTARI, F. Mil platôs: Capitalismo e esquizofrenia. Tradução de Peter Pál Pelbart; Janice Caiafa. Sáo Paulo: Editora 34, 1997. v. 5. (Col. TRANS). DELEUZE, G.; GUATTARI, F. Milplatôs: Capitalismo e esquizofrenia. Tradução de Aurélio Guerra Neto e Célia Pinto Costa. São Paulo: Editora 34, 2004. v. 1. (Col. TRANS). 
EWALD, F. Anatomia e corpos políticos. In: EWALD, F. Foucault, a norma e o direito. Traduçáo de António Fernando Cascais. Lisboa: Vega, 1993. p. 19-57. (Col. Comunicação e Linguagens).

FOUCAULT, M. Vigiar e punir. Traduçáo de Raquel Ramalhete. 23. ed. Petrópolis: Vozes, 2000.

FOUCAULT, M. Os anormais: Curso no Collège de France (1974-1975). Tradução de Eduardo Brandão. São Paulo: Martins Fontes, 2002. Edição estabelecida sob a direção de François Ewald e Alessandro Fontana, por Valério Marchetti e Antonella Salomoni.

FOUCAULT, M. Em defesa da sociedade. Curso no Collège de France (1975-1976). Tradução de Maria Ermantina Galvão. São Paulo: Martins Fontes, 2005a.

FOUCAULT, M. História da loucura na idade clássica. Tradução de José Teixeira Coelho Neto. 8 ed. São Paulo: Perspectiva, 2005b. (Col. Estudos 61, dirigida por J. Guinsburg).

FOUCAULT, M. O poder psiquiátrico: Curso dado no Collège de France (1973-1974). Traduçáo de Eduardo Brandão. São Paulo: Martins Fontes, 2006. Edição estabelecida por Jacques Lagrange sob a direção de François Ewald e Alessandro Fontana. Revisão técnica: Salma Tannus Muchail, Marcio Alves da Fonseca.

GALLIO, G. Nell'impresa sociale. Cooperazione, lavoro, ri-abilitazione, culture di confine nelle politiche di salute mentale. Trieste: Edizione E, 1991.

GOFFMAN, E. Manicômios, prisôes e conventos. Tradução de Dante Moreira Leite. São Paulo: Perspectiva, 1974.

GOFFMAN, E. Estigma: notas sobre a manipulação da identidade deteriorada. São Paulo: Zahar, 1980. PMid:7398269.

KINKER, F. S. Trabalho como produçáo de vida. Revista de Terapia Ocupacional da USP, São Paulo, v. 8, n. 1, p. 42-48, 1997.

KINKER, F. S. O lugar do manicômio: Relato da experiência de desconstrução de um hospital psiquiátrico no interior do Nordeste. 2007. 164 f. Dissertação (Mestrado em Ciências Sociais)-Pontifícia Universidade Católica de São Paulo, São Paulo, 2007.

KINKER, F. S. Fragmentos de uma sociabilidade emergente: a trajetória do Núcleo do Trabalho do Programa de Saúde Mental de Santos (1989-1996). 2011. 261 f. Tese (Doutorado em Ciências Sociais)-Pontifícia Universidade Católica de São Paulo, São Paulo, 2011.

KINOSHITA, R. T. Em busca da cidadania: Desinstitucionalização de um hospital psiquiátrico. In: BRAGA CAMPOS, F. C.; HENRIQUES, C. M. P. (Orgs.). Contra a maré à beira-mar: a experiência do SUS em Santos. São Paulo: Scritta, 1996. p. 39-49.

MORIN, E. A noção de sujeito. In: SCHNITMAN, D. F. (Org.). Novos paradigmas, cultura e subjetividade. Tradução de Jussara Haubert Rodrigues. Porto Alegre: Artes Médicas, 1996. p. 45-58.

MORIN, E. Os desafios da complexidade. In: MORIN, E. A religaçâo dos saberes: Jornadas temáticas idealizadas e dirigidas por Edgard Morin. Tradução de Flávia
Nascimento. Rio de Janeiro: Bertrand Brasil, 2001. p. 559-567.

MORIN, E. O método 4: As ideias, hábitat, vida, costumes, organização. Tradução de Juremir Machado da Silva. 3 ed. Porto Alegre: Sulina, 2002.

NASCIMENTO, S. P. S. O caminhar na desconstrução do modelo de atenção asilar em saúde mental: a experiência de Santos. Revista de Terapia Ocupacional da USP, v. 8, n. 1, p. 5-14, 1997.

NICÁCIO, M. F. S. O processo de transformação da Saúde Mental em Santos: desconstrução de saberes, instituiçôes e cultura. 1994. 155 f. Dissertaçáo (Mestrado em Ciências Sociais)-Pontifícia Universidade Católica de São Paulo, São Paulo, 1994.

NICÁCIO, M. F. S. Utopia da realidade: Contribuiçōes da desinstitucionalização para a invenção de serviços de saúde mental. 2003. 279 f. Tese (Doutorado em Saúde Coletiva)-Faculdade de Ciências Médicas, Universidade Estadual de Campinas, Campinas, 2003. PMid:14576903.

NICÁCIO, M. F. S.; KINKER, F. S. O desafio do viver fora: construindo a cooperativa Paratodos. In: BRAGA CAMPOS, F. C.; HENRIQUES, C. M. P. (Orgs.). Contra a maré à beira-mar: A experiência do SUS em Santos. Sáo Paulo: Scritta, 1996. p. 121-31.

NOGUEIRA, F. O direito ao trabalho: um instrumento no processo de desconstrução do manicômio em Santos, São Paulo. Revista de Terapia Ocupacional da USP, São Paulo, v. 8, n. 1, p. 53-56, 1997.

OGAWA, R. Trabalho: liberdade versus exclusão. Revista de Terapia Ocupacional da USP, São Paulo, v. 8, n. 1, p. 49-52, 1997.

REIS, S. L. C. Da desconstrução do manicômio à construção de um novo modelo de atenção em saúde mental, municipio de Santos no periodo de 1989 a 1996. 1998. 162 f. Dissertação (Mestrado em Medicina Preventiva na USP)-Faculdade de Medicina, Universidade de São Paulo, São Paulo, 1998.

ROBORTELLA, S. C. Relatos de usuários de saúde mental em liberdade: o direito de existir. 2000. 145 f. Dissertaçáo (Mestrado em Saude Coletiva)-Faculdade de Ciências Médicas, Universidade Estadual de Campinas. Campinas, 2000.

ROTELLI, F. A instituição inventada. Tradução de Maria Fernanda de Silvio Nicácio. In: NICÁCIO, M. F. S. (Org.). Desinstitucionalização. São Paulo: Hucitec, 1990. p. 89-100.

ROTELLI, F. Modelli scientifici e complessità. In: rotelli, F. Per la normalità: Taccuino di uno psichiatria: scritti 1967-1993. Milano: Edizione E, 1994. p. 58-63.

ROTELLI, F.; DE LEONARDIS, O.; MAURI, D. Desinstitucionalização, uma outra via: A reforma psiquiátrica italiana no contexto da Europa Ocidental e dos "Países Avançados". In: NICÁCIO, M. F. S. (Org.). Desinstitucionalização. Tradução de Maria Fernanda de Silvio Nicácio. São Paulo: Hucitec, 1990. p. 17-59.

SARACENO, B. Libertando identidades: da reabilitaçáo psicossocial à cidadania possível. Traduçấo de Lúcia Helena Zanetta, Maria do Carmo Rodrigues Zanetta, 
Willians Valentini. Belo Horizonte: Te Corá, Instituto Franco Basaglia, 1999a. Revisão técnica: Ana Maria Fernandes Pitta.

SARACENO, B. La ciudadanía como forma de tolerancia. Revista Tres al Cuarto Actualidad, Psicoanálisis y Cultura, Barcelona, p. 51-57, 1999b.
SARACENO, B. Reabilitação psicossocial: uma estratégia para a passagem do milênio. In: PITTA, A. M. F. (Org.). Reabilitação psicossocial no Brasil. 2. ed. São Paulo: Hucitec, 2001. p. 13-19.

SPINOZA, B. Ética. Tradução de Tomaz Tadeu. Belo Horizonte: Autêntica, 2009.

\section{Notas}

${ }^{1}$ Utilizo a expressão reabilitação psicossocial baseando-me em Saraceno (1999b, 2001), para quem a reabilitação não é uma técnica mas sim uma atitude estratégica, expressa em programas e serviços, produzindo açóes de cuidado a pessoas vulneráveis, que sofreram processos de institucionalizaçâo devido à relação da sociedade com aqueles que vivenciam um sofrimento psíquico grave. Em vez de seguir uma trilha de normalização e adaptação, que vai da desabilidade à habilitação, a reabilitação constitui um processo de descoberta de novas potencialidades e possibilidades através de um processo de mediação e negociação que propóe modificaçóes nos contextos que geram a exclusão e a invalidez. A reabilitação seria então um "[...] processo de reconstrução, um exercício pleno de cidadania, e, também, de plena contratualidade nos três grandes cenários: habitat, rede social e trabalho com valor social.” (SARACENO, 2001, p. 16).

${ }^{2}$ Entretenimento é um termo utilizado por Benedetto Saraceno (1999b, p. 16-17) para expressar o risco que os serviços territoriais podem correr se náo assumirem para si a tarefa de atuar no território, praticando um acompanhamento dos usuários dos serviços nos vários âmbitos da vida. O entretenimento sempre acompanhou a psiquiatria e é um sinal de sua impotência. Significa "manter dentro", "passar o tempo de forma prazerosa”, ou seja, ocupar o tempo dos usuários dos serviços como um fim em si mesmo, sem provocar mudanças nas relaçóes sociais e sendo, efetivamente, formas tolerantes ou opressivas de controle.

${ }^{3}$ Os terapeutas ocupacionais sabem bem o que significa a voracidade das instituiçốes por mecanismos de entretenimento. Sempre lhes foram solicitadas formas de ocupação dos pacientes nas instituiçóes totais, como forma de "afastar pensamentos mórbidos", "diminuir a agressividade", "organizar o eu”, "permitir ao inconsciente exprimir-se", "treinar comportamentos adequados" e toda uma série de motivos que deixavam imunes e escondidas as contradiçóes institucionais, a própria contradição que explica e garante a existência da instituição. Atualmente, em muitos casos, os próprios serviços territoriais e comunitários como os Caps estão sujeitos a cair na armadilha do entretenimento quando substituem a relação com o território e com a existência concreta dos usuários pela excessiva realização de procedimentos grupais, oficinas terapêuticas etc. Tal situação surge muitas vezes como uma forma defensiva de lidar com a angústia do não saber: não saber como dialogar com a complexidade da vida dos usuários, com as questốes que alimentam o sofrimento, com um mundo que parece desértico e pobre de recursos etc. Sem dúvida, esse é um dos importantes desafios da atualidade.

${ }^{4}$ A discussão sobre a quem cabe desenvolver os projetos de trabalho dentro das redes de serviços de saúde mental ainda se encontra em processamento no Brasil. Em muitas cidades, os projetos são instituídos a partir dos próprios Caps. Outras localidades escolhem estrategicamente instituir equipes ou serviços para essa função, como os Centros de Convivência ou os Núcleos de Trabalho. A experiência de Santos optou pela segunda alternativa por entender que o desenvolvimento de projetos de trabalho implica adentrar uma dimensão complexa que exige dos profissionais energia e tempo integral.

${ }^{5}$ Para Spinoza (2009), os afetos podem aumentar ou diminuir a potência de agir. O Conatus, o esforço para perseverar na existência, busca as formas de aumentar nossa potência de agir, pois dela depende a vida.

${ }^{6}$ Os empreendimentos sociais, na perspectiva dos italianos, envolvem não somente a criação de cooperativas sociais (que são instâncias de produção compostas por trabalhadores comuns e pessoas em desvantagem e que, por isso, recebem um tratamento especial do estado e do mercado), mas são máquinas de produzir sociabilidades, instâncias geradoras de experiências produtoras de vida e de novas mensagens ao imaginário social. O caráter ao mesmo tempo público e privado desses empreendimentos aponta uma nova forma de se produzir e de se relacionar socialmente, fomentando ambientes de troca, de cuidado entre pessoas, de descoberta de potencialidades. 